\title{
DOES ENHANCED ELECTROMAGNETIC RADIATION DISTURB HONEYBEES' BEHAVIOUR? OBSERVATIONS DURING NEW YEAR'S EVE 2019
}

\author{
Daniel Favre ${ }^{* 1} \otimes(i D)$, Olle Johansson ${ }^{2}$ \\ ${ }^{* 1}$ A.R.R.A., P.O. box 494, CH-1860 Aigle, Switzerland \\ ${ }^{2}$ Associate Professor, retired from the Karolinska Institute (in Nov 2017, still active), Department \\ of Neuroscience, head of The Experimental Dermatology Unit, Stockholm, Sweden, and Adjunct \\ Professor, previously at the Royal Institute of Technology, Stockholm, Sweden
}

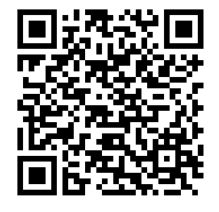

DOI: https://doi.org/10.29121/granthaalayah.v8.i11.2020.2151

Article Type: Research Article

Article Citation: Daniel Favre, and Olle Johansson. (2020). DOES

ENHANCED ELECTROMAGNETIC RADIATION DISTURB HONEYBEES' BEHAVIOUR? OBSERVATIONS DURING NEW YEAR'S EVE 2019. International Journal of Research GRANTHAALAYAH, 8(11), 7-14. https://doi.org/10.29121/granthaa layah.v8.i11.2020.2151

Received Date: 26 October 2020

Accepted Date: 20 November 2020

Keywords:

Honeybees

Sounds

Worker Piping

RF-EMF

New Year's Eve

Anthropogenic Electrosmog

\section{ABSTRACT}

Insects, and especially honeybees, are under major threat everywhere around the globe. Current studies lack in the consideration of potential effects which may directly affect other organisms or ecosystems, because of the verPy limited attention which is usually received by the potential adverse ecological effects of radiofrequency electromagnetic fields. Here, it is hypothesized that planetary enhancement of electromagnetic radiation produces a disturbing pollution for honeybees. In order to test this hypothesis, a bi-directional wide frequency range microphone was placed during the New Year's Eve night 2019 in a honeybee hive, in order to detect and analyze potential changes in the acoustic behaviour of the bees due to increased phone induced RF- EMF radiation. It was observed that the honeybees produced strong worker piping signals. Such signals are typically produced shortly before takeoff of a swarm, or as the sign of a disturbed colony. It is therefore hypothesized that planetary enhancement of electromagnetic radiation produces a disturbing pollution for honeybees, such as during the New Year's Eve night. Evidence of proof of such electromagnetic waves taking place at New Year's Eve should be investigated worldwide during forthcoming similar events based on a global network of long term EM measurements.

\section{INTRODUCTION}

Honeybees are under major threat everywhere around the globe [1], [2]. The so-called colony collapse disorder (CCD) is a recent phenomenon [3]. Current theories about the potential cause(s) of CCD essentially include increased losses due to the invasive varroa mite, pesticide poisoning, potential immune-suppressing stress on bees, drought, monocultural practices, migratory stress due the moving of the bees in long distances, and increased transmission of pathogens [4], [5]. Furthermore, radiation from mobile phones and mast antennas could also have contributed to the dramatic decline in insect populations, as revealed by a recent meta-analysis; indeed, increased exposure to electromagnetic radiation is "probably having a negative impact on the insect world", according to a recent study $[6]$.

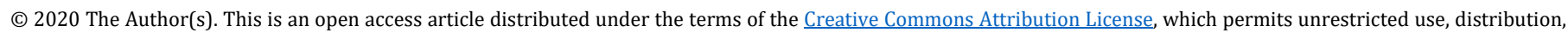
and reproduction in any medium, provided the original authors and source are credited. 
Thielens et al. [7] studied the effects of radio-frequency electromagnetic fields (RF-EMFs) on the Western honeybee. They showed that a relatively small shift of $10 \%$ of environmental incident power density from frequencies below $3 \mathrm{GHz}$ to higher frequencies will lead to a relative increase in absorbed power of a factor higher than 3. In 2011, I have shown that active mobile phone handsets have a dramatic impact on the behaviour of bees, namely by inducing the worker piping signal [8]. These initial observations were substantiated by additional experiments that were performed with the controlled enhancement of the local RF-EMF signals [9]. In natural conditions, worker piping either announces the swarming process of the bee colony or is a signal of a disturbed bee colony [10], [11].

In order to assess, whether the increased radiofrequency electromagnetic radiation in the environment has an impact on the behaviour of honeybees, a broad spectral frequency microphone was placed in a hive during the New Year's Eve night of 2019, to investigate whether and to what degree the increased amount of local wireless communications might have an effect on the honeybees' behaviour around midnight, local time.

\section{MATERIALS AND METHODS}

The recording of a honeybee colony during the New Year's Eve 2019 took place in a rural area of Switzerland, close to the city of Montreux and at an altitude of $960 \mathrm{~m}$ above sea level. This location is surrounded by small mountains (Les Pléiades, Le Folly and Le Cubly, at 1362, 1730 and $1187 \mathrm{~m}$ above sea level, respectively). There is only one local emitting antenna in direct view (CH1093+ / LV95 ; https://www.bakom.admin.ch/bakom/en/homepage/frequencies-and-antennas/location-of-radio-

transmitters.html), located more than $800 \mathrm{~m}$ away from the hive (Fig. 1a). The device employed for the recording of the honeybees' sounds consisted of a bidirectional compact microphone (Olympus ME-31) with frequency response from 70 to $15,000 \mathrm{~Hz}$ connected to a vocal recorder (Olympus LS-11). The microphone was placed in the bottom part of the hive (Figs. 1b and c). The vocal recorder was connected to an external battery (Panasonic LC-R123R4P; https://na.industrial.panasonic.com/) via a 12V-to-4.5V voltage converter (Dupertuis Electronique S.A., Lausanne, Switzerland) (Fig. 1d).

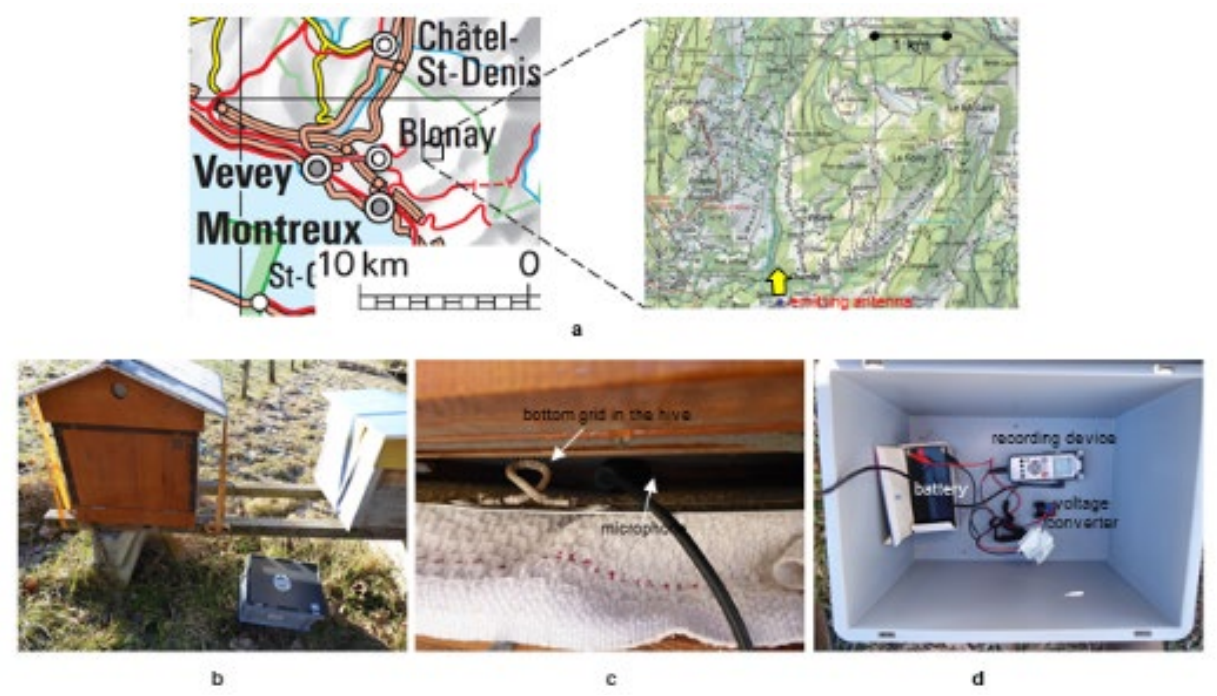

Figure 1: Location of the honeybee colony and experimental setup. a, Overview of the measurement location (source : Swiss Federal Office of Topography,

https://shop.swisstopo.admin.ch/en/products/maps/overview/municipality_map ; geodata (C swisstopo). The rural location at $1000 \mathrm{~m}$ above sea level is lying within mountains (Les Pléiades, Le Folly and Le Cubly); there is only one emitting antenna mast (for 2G, 3G and 4G) in direct view, more than $800 \mathrm{~m}$ away from the honeybee colony. b, Experimental setup, with positioning of the microphone under the bottom grid in the hive, above which is the honeybee colony. c, Microphone positioning in the back side of the hive (Dadant-Blatt model). $\mathbf{d}$, Set up of the recording device. Electric current is provided by a 12 Volts battery and the voltage necessary for the recording device is set to 4.5 Volts with the help of a voltage converter. 
The recorded signal was digitized as a Waveform audio file format sound file with 44,1 kHz recording mode. The open source, cross platform audio software Audacity (https://www.audacityteam.org/) was employed for the manual analysis of the sound files and for the generation of the audiograms (also called sonograms) and spectrograms (oscillograms). The computer program FFT Properties 5.0 (Dew Research LLC, SLO-3210 Slovenske Konjice, Slovenia) was employed for the generation and the analysis of the orbital phase (which is a visualization of the signal strength during a given period). Intensity values of audiograms might slightly vary throughout the whole recordings in the hive, depending on the clustering of the bees in the hive during winter. The sound files are freely available at https://doi.org/10.5061/dryad.5mkkwh748. In the geographic area where the recordings took place, the bees (Apis mellifera carnica) usually begin to forage to collect nectar and pollen in early March, depending on the weather conditions. All applicable national guidelines for the care and use of honeybees were followed.

\section{RESULTS AND DISCUSSIONS}

The fundamental frequency of Apis mellifera carnica was in the range of 70 to $100 \mathrm{Hertz}(\mathrm{Hz})$. Dramatic changes in the fundamental intensity and frequency patterns of the sounds produced in the hive were recorded before, during and after the local New Year's Eve. It was indeed observed based on the recorded signals that the honeybees were significantly disturbed around midnight (local time), since the colony emitted a strong and long lasting (about 15 minutes) worker piping signal (Fig. 2).

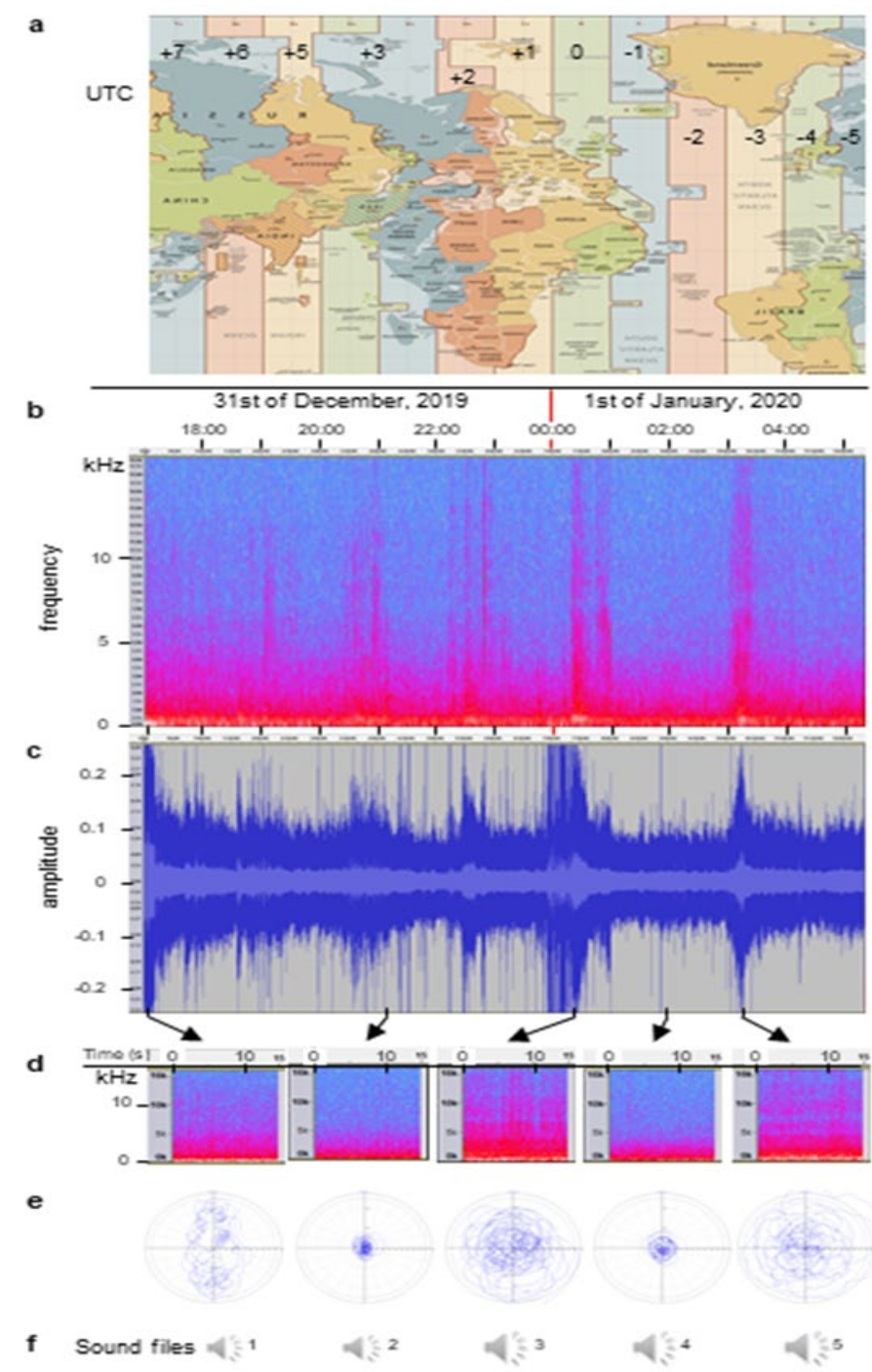

Figure 2: World time zones correlated with spectrogram and audiogram of hive sounds. a, World time zones (source: Map of current official time zones, US Central Intelligence Agency, 
https://en.wikipedia.org/wiki/File:World_Time_Zones_Map.png from the freely licensed media file repository Wikimedia Commons) with Coordinated Universal Time (UTC). The map is flipped horizontally in order to reflect the progression of the New Year's Eve around the terrestrial globe. b. Spectrogram of honeybee colony sounds. Spectrogram is reported in kiloHertz (kHz). Local time is reported horizontally, from the left to the right. Local New Year's Eve at 00:00 (24-hour clock) is indicated with a vertical red line. c, Audiogram of honeybee colony sounds. Audiogram is normalized (-0.25 to 0.25). Local time is corresponding to Panel $\mathbf{b}$. d, Spectrograms from five different time points. Spectrograms are reported in kiloHertz $(\mathrm{kHz})$. Sounds lasting fifteen seconds each and starting at 17:03:00, 21:40:00, 01:22:55, 03:53:50 and 05:16:35 (hh.mm.ss) were analyzed. e, Orbital phase analyses of honeybees' sounds (see panel d). f, Sound files (see panel d).

Very surprisingly, the bees seemed to have also been disturbed on several other occasions before and after local midnight, as seen with the increase of the sound intensities and also the frequencies produced by the honeybee colony (Figs. 2a and 2b, respectively). These sounds might be correlated to the succeeding locations of the New Year's Eve celebrations around the globe : about seven (China), five (India), three and a half (Iran), three (Center of Russia, Saudi Arabia, East of Africa, Madagascar), two (Finland, Baltic States, Ukraine, Turkey, Bulgaria, Romania, etc.) hours before, and about one (United Kingdom) and three (Brazil, Argentina) hours after the local New Year's Eve, respectively. Listening to the sound files themselves further substantiates these observations (Figs. 2d and 2e) which to the best of these authors' knowledge, cannot be explained by natural causes.

For controls, twelve additional and similar recordings were performed with the same hive throughout the following weeks until mid-February. This revealed that the patterns of the sounds and frequencies produced by the honeybee colony did not show the peaks that were observed during the night of the New Year's Eve (Fig. 3).

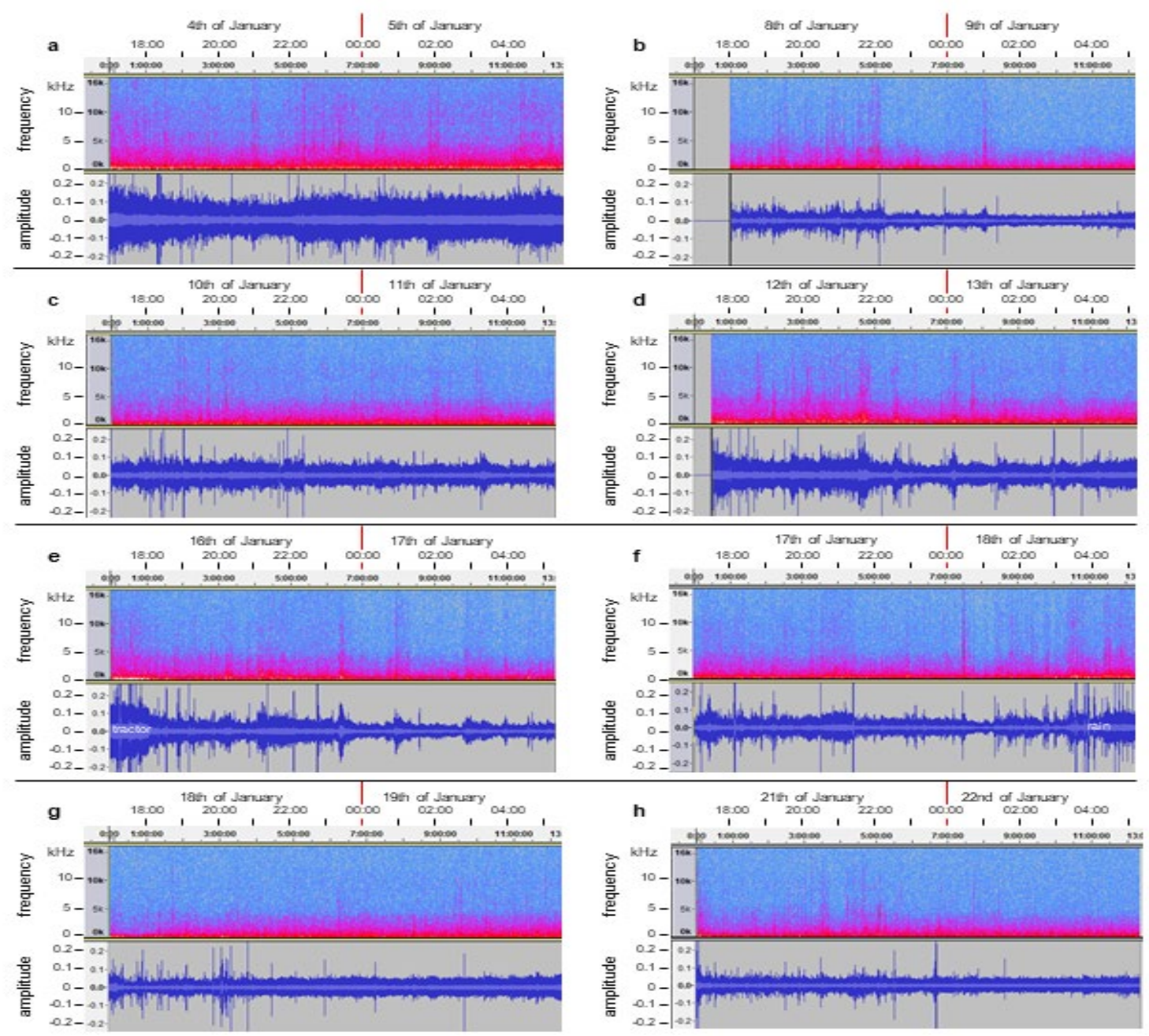

Figure 3: Spectrograms and audiograms of hive sounds. Spectrograms are reported in kiloHertz (kHz). Audiograms are normalized (-0.2 to 0.2 ). Local time is reported horizontally, from the left to the right. Local 
midnight (00:00 ; 24-hour clock) is indicated with a vertical red line. a, 4 to 5 of January. b, 8 to 9 of January. c, 10 to 11 of January. d, 12 to 13 of January. e, 16 to 17 of January. A tractor was noisy in the surroundings. f, 17 to 18 of January. Rain in the early morning was audible. g, 18 to 19 of January. $\mathbf{h}, 21$ to 22 of January. All dates are in the year 2020 .

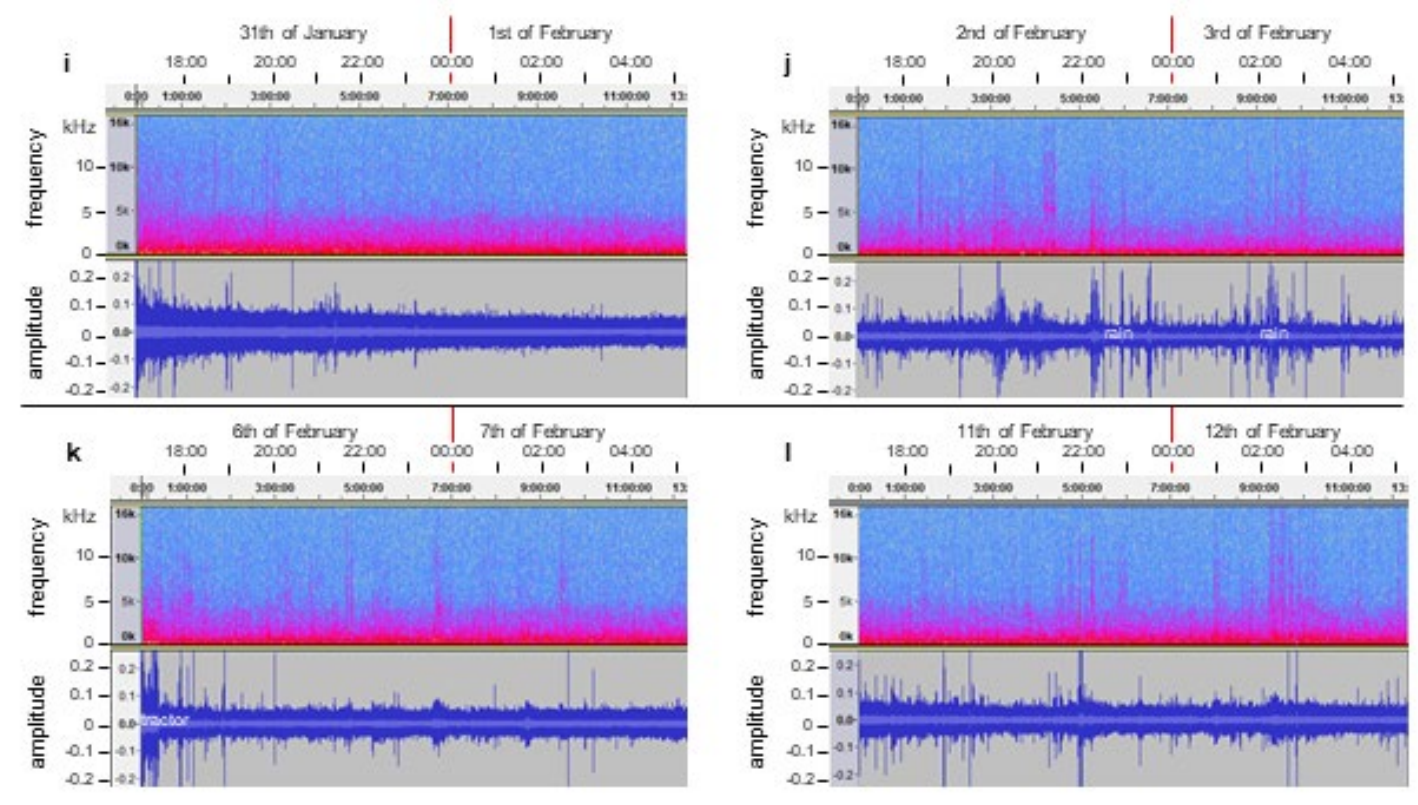

Figure 3 (continued): Spectrograms and audiograms of hive sounds. Spectrograms are reported in kiloHertz $(\mathrm{kHz})$. Audiograms are normalized ( -0.2 to 0.2$)$. Local time is reported horizontally, from the left to the right. Local midnight $(00: 00 ; 24$-hour clock) is indicated with a vertical red line. i, 31 of January to 1 of February. j, 2 to 3 of

February. Rain during the night. k, 6 to 7 of February. l, 11 to 12 of February. All dates are in the year 2020.

It is hypothesized here that the honeybees were subjected not only to local but to global anthropogenic environmental RF-EMFs exposure occurring from New Year's Eve festivities around the globe. Indeed, the worker piping signals produced by honeybees is usually a signal that is produced shortly before takeoff of a swarm [10], or is associated with disturbance of the hive by, for example, intruders or jarring [11]. The induction of honeybee worker piping by enhanced electromagnetic fields might have dramatic consequences in terms of colony losses due to unexpected swarming. It is therefore time to assess the planetary electromagnetic pollution, since the Internet of Things and 5G will add millions more radiofrequency transmitters around and radiating with unprecedented increased power density above us, and since radio frequency electromagnetic fields (RF-EMF) have increased by several orders of magnitude over the last 50 years [12]. Current studies lack in the consideration of potential effects which may directly affect other organisms or ecosystems, because of the very limited attention which is usually received by the adverse ecological effects of RF-EMF [13]. Hallmann et al. have observed a seasonal decline of 76\%, and mid-summer decline of $82 \%$ in flying insect biomass over the 27 years of their study [14]. These authors showed that this decline was apparent regardless of habitat type, while changes in weather, land use, and habitat characteristics cannot explain this overall decline.

It is obvious that in the future, thorough independent scientific investigations must be conducted in order to confirm or refute the working hypothesis : do RF-EMFs emitted not only locally, but worldwide, have the ability to disturb the behavior of honeybees? Several critical parameters should be concomitantly analysed in the close vicinity of the honeybees participating in these studies, such as : i) the permanent measurement of the levels of exposure to radiofrequency electromagnetic radiations (around various frequency bands) ; ii) the analysis of the environmental electric and magnetic fields, and their variations ; iii) the examination of the putative involvement of natural atmospheric events such as, for example, the variations in the radio atmospheric signals, the so-called spherics [15].

There might be an unknown planetary electromagnetic mechanism for the generation of the observed sound effects in a bee colony. Indeed, honeybees have magnetic remanence [16] and can be trained to respond to very small 
changes in geomagnetic-field intensity, with the detection of an anomaly of $0.06 \%$ of background [17]. Honeybees do possess a magnetoreception system [18] and have been shown capable of detecting weak electric fields [19]. Evidence of proof of such electromagnetic waves taking place at New Year's Eve should be investigated worldwide during forthcoming similar events based on a global network of long term EM measurements. Protocols and methodologies are available for thoroughly performing such investigations [20], [21], [22].

Further verification of the above working hypothesis by implementing such measurements in a global monitoring network will be important for a mechanistic understanding of the interaction of RF fields with ecosystems [23].

\section{CONCLUSIONS \& RECOMMENDATIONS}

The present study has revealed disturbing behaviour by honeybees which were very likely caused by increased wireless phone EM radiation during New Year's Eve celebrations around the globe. To the best of these authors' knowledge, this behaviour could not be explained by natural causes.

The forthcoming deployment of the $5 \mathrm{G}$ (fifth generation) wireless network, including $5 \mathrm{G}$ from space satellites, will increase exposure to radio frequency (RF) radiation on top of the $2 \mathrm{G}, 3 \mathrm{G}$ and $4 \mathrm{G}$ networks for telecommunications already in place. These RF radiations might be harmful for the biosphere. There is therefore an urgent need to address the so-called anthropogenic electrosmog [12]. The risk assessment and regulation of anthropogenic electromagnetic fields should be carefully evaluated and coordinated under international scrutiny.

Increasing RF-EM radiation power worldwide and the upcoming $5 \mathrm{G}$ rollout may present a serious challenge not only for honeybees but public health in general [24].

\section{APPENDICES}

Supplementary Materials: The original sound files are available online at https://doi.org/10.5061/dryad.5mkkwh748

Appendix A

Audio file 1. Recording of honey bees during the New Year's Eve 2019. Recording is starting at 5:03:00 AM and is lasting 15 seconds

Audio file 2. Recording of honey bees during the New Year's Eve 2019. Recording is starting at 9:40:00 AM and is lasting 15 seconds

Audio file 3. Recording of honey bees during the New Year's Eve 2019. Recording is starting at 00:22:55 PM and is lasting 15 seconds

Audio file 4. Recording of honey bees during the New Year's Eve 2019. Recording is starting at 01:53:50 PM and is lasting 15 seconds

Audio file 5. Recording of honey bees during the New Year's Eve 2019. Recording is starting at 03:16:35 PM and is lasting 15 seconds

Large audio file entitled "Honeybees New Year's Eve 2019 Favre". Full recording of the honeybees in the hive, starting 17.00 local time the 31st of December, 2019.

\section{AUTHOR CONTRIBUTIONS}

The first author is Dr. in Biology, teacher, independent researcher, apiary adviser in the canton de Vaud (Switzerland), president (since 2010) of the not-for-profit association Alerte Romande aux Rayonnements Artificiels (A.R.R.A., formerly A.R.A; www.alerte.ch), and member of the scientific advisory board of the not-for-profit association FreeTheBees (www.freethebees.ch). The second author is an Associate Professor, retired from the Karolinska Institute (in Nov 2017, still active), Department of Neuroscience, head of The Experimental Dermatology Unit, Stockholm, Sweden, and Adjunct Professor, previously at the Royal Institute of Technology, Stockholm, Sweden. 
Daniel Favre, and Olle Johansson

\section{SOURCES OF FUNDING}

This research received no specific grant from any funding agency in the public, commercial, or not-for-profit sectors.

\section{CONFLICT OF INTEREST}

The authors have declared that no competing interests exist.

\section{ACKNOWLEDGMENT}

This work was performed under the full responsibility of the two authors. Daniel Favre is very grateful to JeanClaude Perez, Ph.D. (Bordeaux, France) for his support in the correction of the manuscript. The International 5G Appeal (https://www.5gspaceappeal.org/) gave us the final inspiration for undertaking this current research study.

\section{REFERENCES}

[1] Brown, M.J., Dicks, L.V., Paxton, R.J., Baldock, K.C., Barron, A.B., Chauzat, M.P., Freitas, B.M., Goulson, D., Jepsen, S., Kremen, C., Li, J., Neumann, P., Pattemore, D. E., Potts, S. G., Schweiger, O., Seymour, C. L., Stout, J. C. A Horizon Scan of Future Threats and Opportunities for Pollinators and Pollination. PeerJ., 4, 2016, e2249, doi:10.7717/peerj.2249.

[2] Decourtye, A., Alaux, C., Le Conte, Y., Henry, M. Toward the protection of bees and pollination under global change: present and future perspectives in a challenging applied science. Current Opinion in Insect Science, 35, 2019, 123-131, doi:https://doi.org/10.1016/j.cois.2019.07.008.

[3] Vanengelsdorp, D., Evans, J.D., Saegerman, C., Mullin, C., Haubruge, E., Nguyen, B.K., Frazier, M., Frazier, J., CoxFoster, D., Chen, Y., et al. Colony collapse disorder: a descriptive study. PloS one, 4, e6481, 2009, doi:10.1371/journal.pone.0006481.

[4] Genersch, E. Honey Bee Pathology: Current Threats to Honey Bees and Beekeeping. Applied Microbiology and Biotechnology, 87, 2010, 87-97, doi:10.1007/s00253-010-2573-8.

[5] Watson, K.; Stallins, J.A. Honey Bees and Colony Collapse Disorder: A Pluralistic Reframing. Geography Compass, 10, 2016, 222-236, doi:10.1111/gec3.12266.

[6] Thill, A. Biologische Wirkungen Elektromagnetischer Felder auf Insekten. umwelt • medizin · gesellschaft, 33, 2020, 1-28.

[7] Thielens, A., Greco, M.K., Verloock, L., Martens, L., Joseph, W. Radio-Frequency Electromagnetic Field Exposure of Western Honey Bees. Scientific Reports, 10, 2020, 461, doi:10.1038/s41598-019-56948-0.

[8] Favre, D. Mobile Phone-Induced Honeybee Worker Piping. Apidologie, 42, 2011, 270-279, doi:10.1007/s13592-011-0016-X.

[9] Favre, D. Disturbing Honeybees' Behavior with Electromagnetic Waves: a Methodology. Journal of Behavior 2(2), 2017.

[10] Rangel, J., Seeley, T.D. The Signals Initiating the Mass Exodus of a Honeybee Swarm from its Nest. Animal Behaviour, 76, 2008, 1943-1952, doi:DOI 10.1016/j.anbehav.2008.09.004.

[11] Wenner, A.M. Sound Communication in Honeybees. Scientific American, 210, 1964, 116-124.

[12] Bandara, P., Carpenter, D.O. Planetary Electromagnetic Pollution: it is Time to assess its Impact. The Lancet Planetary Health, 2, 2018, e512-e514, doi:10.1016/S2542-5196(18)30221-3.

[13] Cucurachi, S., Tamis, W.L., Vijver, M.G., Peijnenburg, W.J., Bolte, J.F., de Snoo, G.R. A Review of the Ecological Effects of Radiofrequency Electromagnetic Fields (RF-EMF). Environment international, 51, 2013, 116-140, doi:10.1016/j.envint.2012.10.009.

[14] Hallmann, C.A., Sorg, M., Jongejans, E., Siepel, H., Hofland, N., Schwan, H., Stenmans, W., Muller, A., Sumser, H., Horren, T., Goulson, D., de Kroon, H. More than 75 percent decline over 27 years in total flying insect biomass in protected areas. PloS one, 12, 2017, e0185809, doi:10.1371/journal.pone.0185809. 
[15] Panagopoulos, D.J., Balmori, A. On the biophysical mechanism of sensing atmospheric discharges by living organisms. The Science of the Total Environment, 599-600, 2017, 2026-2034, doi:10.1016/j.scitotenv.2017.05.089.

[16] Gould, J.L., Kirschvink, J.L., Deffeyes, K.S. Bees Have Magnetic Remanence. Science, 201, 1978, 1026-1028.

[17] Walker, M.M., Bitterman, M.E. Honeybees Can Be Trained to Respond to Very Small Changes in GeomagneticField Intensity. Journal of Experimental Biology, 145, 1989, 489-494.

[18] Hsu, C.Y., Ko, F.Y., Li, C.W., Fann, K., Lue, J.T. Magnetoreception System in Honeybees (Apis mellifera). PloS one, 2, e395, 2007, doi:10.1371/journal.pone.0000395.

[19] Greggers, U., Koch, G., Schmidt, V., Durr, A., Floriou-Servou, A., Piepenbrock, D., Gopfert, M.C., Menzel, R. Reception and Learning of Electric Fields in Bees. Proceedings of the Royal Society B - Biological Sciences, 280, 2013, 20130528, doi:10.1098/rspb.2013.0528.

[20] Bhatt, C.R., Redmayne, M., Abramson, M.J., Benke, G. Instruments to Assess and Measure Personal and Environmental Radiofrequency-Electromagnetic Field Exposures. Australasian Physical \& Engineering Sciences in Medicine, 39, 2016, 29-42, doi:10.1007/s13246-015-0412-z.

[21] Gajšek, P., Ravazzani, P., Wiart, J., Grellier, J., Samaras, T., Thuróczy, G. Electromagnetic Field Exposure Assessment in Europe Radiofrequency fields (10 MHz-6 GHz). Journal of Exposure Science \& Environmental Epidemiology, 25, 2015, 37-44, doi:10.1038/jes.2013.40.

[22] Röösli, M., Frei, P., Bolte, J., Neubauer, G., Cardis, E., Feychting, M., Gajsek, P., Heinrich, S., Joseph, W., Mann, S., Martens, L., Mohler, E., Parslow, R. C., Poulsen, A. H., Radon, K., Schüz, J., Thuroczy, G., Viel, J.-F., Vrijheid, M. Conduct of a Personal Radiofrequency Electromagnetic Field Measurement Study: Proposed Study Protocol. Environmental Health, 9:23, 2010, 23, doi:10.1186/1476-069X-9-23.

[23] Vanbergen, A.J., Potts, S.G., Vian, A., Malkemper, E.P., Young, J., Tscheulin, T. Risk to Pollinators from Anthropogenic Electro-Magnetic Radiation (EMR): Evidence and Knowledge Gaps. The Science of the Total Environment, 695, 2019, 133833, doi:10.1016/j.scitotenv.2019.133833.

[24] Russell, C.L. 5 G Wireless Telecommunications Expansion: Public Health and Environmental Implications. Environmental Research, 165, 2018, 484-495, doi:https://doi.org/10.1016/j.envres.2018.01.016. 